\title{
Seamless transfer with interactive compensation algorithm for three-phase grid-connected inverter
}

.

- Thanh-Vu Tran

Eastern International University, Vietnam.

- Dinh-Tuyen Nguyen

- Dzung Phan Quoc

Ho Chi Minh city University of Technology, VNU-HCM, Vietnam.

(Manuscript Received on July 15, 2015, Manuscript Revised August 30, 2015)

\begin{abstract}
This paper proposes an interactive control algorithm for seamless transfer of three-phase grid-connected converter between grid-tide mode and stand-alone mode. In order to archive a smooth transfer between two modes, the voltage controller and current controller are designed to generate the output voltage reference of PWM with no interrupted transition during islanding operation and grid connected

operation. Additionally, a suitable phaselocked loop (PLL) algorithm is posed to obtain the phase angle of grid voltage continuously during operation time even if the utility outages. With the proposed algorithm, the control algorithm guarantees a smooth profile voltage across the local load when the grid is being disconnected or reconnected. In this paper, the simulation and experiment results verify the proposed method.
\end{abstract}

Keywords: distributed power generation, inverters, phase locked loops, grid-connected converter, power supply quality, voltage control, current control.

\section{INTRODUCTION}

Islanding operation occurs when DG system is disconnected from the main remainder of power system. Because of maintenance or normal faults, islanding operation can be interrupted intentionally by the customer. Therefore, during the transition of system, the grid-connected inverter should be controlled properly to keep supplying power into distribution networks. This islanding operation is called intentional islanding. However, islanding operation occurs in a power system due to lightning, animal contact, tree contact, vehicle strikes, and other causes are inadvertent. The protective devices such as overcurrent devices, circuit breakers, reclosers, and fuses are used to isolate the faulted section of feeder from the normal source of energization, the substation. Ideally, the fault should be detected quickly by the DG protection system and the DG needs to be tripped as soon as possible [22]. This islanding operation is considered as an unintentional islanding [13]-[16]. These islands extremely cause a hazard risk to safety and 
equipment, especially in unintentional islanding operation.

Basically, when an islanding operation occurs, the DG system lead to change its controller from current-controlled mode to voltage-controlled mode. In the grid-tied mode, the grid-connected inverter should operate in current-controlled mode to inject power into the grid. On the other hand, the grid-connected inverter operates in voltage-controlled mode to regulate the local load during interruption of utility power. The transfer between two operation modes usually causes the current and voltage of local load spike during the switching process because the difference of two output controllers. The utility-interactive inverters for distributed energy systems presented in the literature [1]-[5] have the capability to operate in grid-tied and offgrid modes but they did not propose any procedure for transition between two modes. A proposed smooth sequence for transition between grid-tied and off-grid is addressed and implemented in [6]-[7]. In order to reduce the turn-off time for static switches (SCR), [8] presented a control technique by controlling the voltage of grid-side inductor through the output voltage of inverter to reduce quickly the grid current, which results in quick disconnection. The limitation of inrush currents has been proposed to ride through a grid fault conditions in [9]. However, the control methods for transition between two modes proposed in [6]-[9] have a difference between the output of voltage controller and the output of current controller when transition occurs, which cause the spikes when transfer from one mode to another mode. A control method has been proposed in [10] to reduce the affection of two controllers by using both current controller and voltage controller in both grid-tied mode and off-grid mode. The transition of two modes is controlled at zerocrossing of the grid voltage and at zero-crossing of the grid current, so it only uses well in singlephase grid-interactive inverters. An Indirect current control algorithm for seamless transfer of three-phase utility-interactive voltage source inverters is proposed in [11]-[12] by controlling the capacitor voltage can guarantee no transition between two modes but the indirect control system need to be adjusted the parameters of the controller when the working condition is changed by time, temperature...

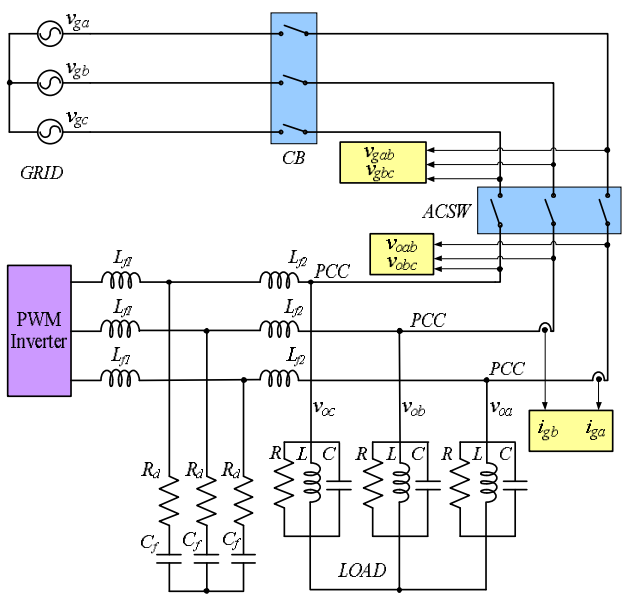

Figure 1. Configuration of three-phase gridinteractive VSI.

This paper proposes a control algorithm for seamless transfer of three-phase grid-interactive inverter between current-controlled and voltage controlled modes in unintentional islanding. The algorithm control guarantees a smooth profile voltage across the local load when the grid is being disconnected or reconnected. The simulation and experiment results have been presented to verify the proposed method.

\section{TOPOLOGY OF PROPOSED THREE- PHASE INVERTER}

Figure 1 shows the configuration of threephase grid-interactive VSI with a DC source that is considered as a micro source, a three-phase LCL filter and three-phase local load. The 
distributed system is connected to the power system through the switches. The switch $\mathrm{CB}$ is used for separating the DG from power system when a fault is detected. The protective device ACSW presents the utility outages when any fault occurs inadvertently at any point of power system before the main bus.

\section{CONTROL STRATEGY}

\subsection{Phase-Locked Loop Algorithm}

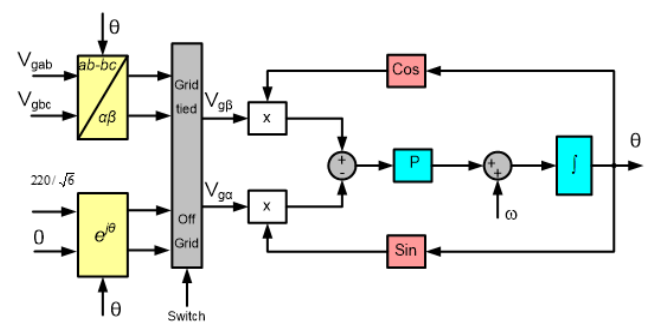

Figure 3. Block diagram of PLL algorithm.

The PLL algorithm is designed to obtain the phase angle of grid voltage $\theta$ continuously during operation time even if the grid voltage is not available. The proposed PLL algorithm using the alpha-beta components in stationary reference frame of three phase input voltage is shown in Figure 3.

$$
\left[\begin{array}{l}
V_{g \alpha} \\
V_{g \beta}
\end{array}\right]=\left[\begin{array}{cc}
\frac{2}{3} & \frac{1}{3} \\
0 & \frac{1}{\sqrt{3}}
\end{array}\right]\left[\begin{array}{l}
V_{g a b} \\
V_{g b c}
\end{array}\right]
$$

In the stand-alone mode, the line voltage $V_{g a b}$ and $V_{g b c}$ are sampled and transformed into $V_{g \alpha}$ and $V_{g \beta}$ using Clarke's transformation (1). In the gridtied mode, the alpha-beta voltage $V_{g \alpha}$ and $V_{g \beta}$ are generated the desired voltage using Park's transformation (2).

$$
\left[\begin{array}{c}
V_{g \alpha} \\
V_{g \beta}
\end{array}\right]=\left[\begin{array}{cc}
\cos (\theta) & -\sin (\theta) \\
\sin (\theta) & \cos (\theta)
\end{array}\right]\left[\begin{array}{c}
220 / \sqrt{6} \\
0
\end{array}\right]
$$

In grid-tied mode, $V_{g \alpha}$ and $V_{g \beta}$ can be described as (3) and (4), respectively. Phase detector $\Delta \omega$ in this mode is archived by the difference between $V_{g \alpha}$ multiply by $\sin (\theta)$ and $V_{g \beta}$ multiply by $\cos (\theta)$ as shown in (5).

$$
\begin{gathered}
V_{g \alpha}=\frac{2}{3} V_{g a b}+\frac{1}{3} V_{g b c}=V_{m} \cos \left(\theta_{g}\right) \\
V_{g \alpha}=\frac{1}{\sqrt{3}} V_{g b c}=V_{m} \sin \left(\theta_{g}\right) \\
\Delta \omega=V_{g \beta} \cos (\theta)-V_{g \alpha} \sin (\theta)=V_{m} \sin \left(\theta_{g}-\theta\right)
\end{gathered}
$$

In off-grid mode, the utility voltage is not available, so the switch signal will be changed. In this case, $V_{g \alpha}$ and $V_{g \beta}$ can be replaced by desired value and shown as (6) and (7), respectively. Phase detector $\Delta \omega$ in this mode is also archived by the difference between $V_{g \alpha}$ multiply by $\sin (\theta)$ and $V_{g \beta}$ multiply by $\cos (\theta)$ as shown in (8).

$$
\begin{aligned}
& V_{g \alpha}=\frac{220}{\sqrt{6}} \cos \left(\theta_{g}\right) \\
& V_{g \alpha}=\frac{220}{\sqrt{6}} \sin \left(\theta_{g}\right)
\end{aligned}
$$

$\Delta \omega=V_{g \beta} \cos (\theta)-V_{g \alpha} \sin (\theta)=\frac{220}{\sqrt{6}} \sin \left(\theta_{g}-\theta\right)$

(8)

A $\mathrm{P}$ controller is used to regulate $\Delta \omega$ to zeros and then the output of this $\mathrm{P}$ controller is added to the fundamental angular frequency of the utility voltage. It is then integrated to phase angle $\theta$.

\subsection{Voltage controller}

The voltage controller is used in stand-alone mode to regulate the output voltage of local load when grid is not available. The block diagram of the voltage controller is shown in Figure 4.

$$
\begin{gathered}
{\left[\begin{array}{l}
V_{o \alpha} \\
V_{o \beta}
\end{array}\right]=\left[\begin{array}{cc}
\frac{2}{3} & \frac{1}{3} \\
0 & \frac{1}{\sqrt{3}}
\end{array}\right]\left[\begin{array}{l}
V_{o a b} \\
V_{o b c}
\end{array}\right]} \\
{\left[\begin{array}{l}
V_{o d} \\
V_{o q}
\end{array}\right]=\left[\begin{array}{cc}
\cos \theta & -\sin \theta \\
\sin \theta & \cos \theta
\end{array}\right]\left[\begin{array}{l}
V_{o \alpha} \\
V_{o \beta}
\end{array}\right]}
\end{gathered}
$$

The output voltage $\mathrm{V}_{\mathrm{o}}$ from the PCC, which has been transformed into a stationary frame by 
transformation (9), (10), is fed back and compared with the reference voltage $V_{g}$ from PLL controller. The comparisons generate the voltage errors that are transformed into a synchronous frame by the Park's transformation (10) and then are passed to the voltage regulator using PI controller. The dc quantities, which are $\mathrm{V}_{\mathrm{dmv}}$ and $\mathrm{V}_{\mathrm{qmv}}$, are added by the other dc quantities, which are $\mathrm{V}_{\mathrm{dm}}$ and $\mathrm{V}_{\mathrm{qm}}$, to generate the voltage references in $\mathrm{dc}$ quantities and then are transformed into a stationary by the inverse of Park's transformation. The final dc-quantities are utilized as command voltages for generating PWM voltages. In this stand-alone mode, $V_{\mathrm{dmc}}$ and $\mathrm{V}_{\mathrm{qmc}}$ will be not changed because the current regulator is not operating; therefore the output voltage at $\mathrm{PCC}$ are regulated by only $\mathrm{V}_{\mathrm{dmc}}$ and $\mathrm{V}_{\mathrm{qmc}}$.

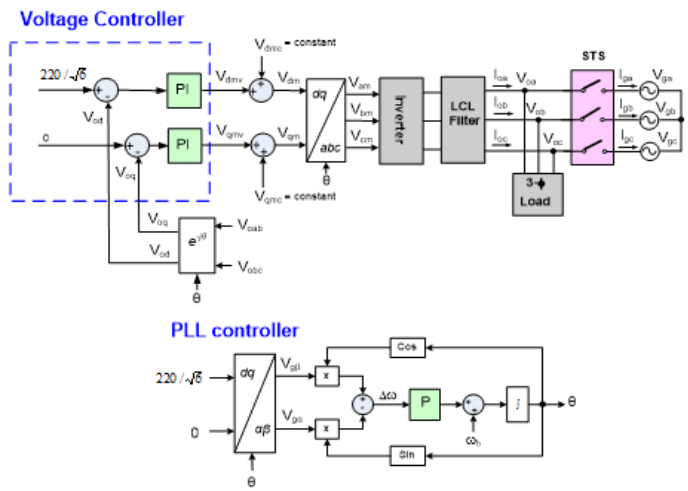

Figure 4. Block diagram for stand-alone mode

$$
\begin{aligned}
& {\left[\begin{array}{l}
V_{\alpha} \\
V_{\beta}
\end{array}\right]=\left[\begin{array}{cc}
\cos \theta & -\sin \theta \\
\sin \theta & \cos \theta
\end{array}\right]\left[\begin{array}{l}
V_{d m} \\
V_{q m}
\end{array}\right]} \\
& {\left[\begin{array}{l}
V_{a m} \\
V_{b m} \\
V_{c m}
\end{array}\right]=\left[\begin{array}{cc}
1 & 0 \\
-\frac{1}{2} & \frac{\sqrt{3}}{2} \\
-\frac{1}{2}-\frac{\sqrt{3}}{2}
\end{array}\right]\left[\begin{array}{l}
V_{\alpha} \\
V_{\beta}
\end{array}\right]}
\end{aligned}
$$

\subsection{Current controller}

Figure 5 shows the block diagram of the current controller. In the grid-tied mode, the current controller is used to control the injected current to the grid side.

$$
\left[\begin{array}{c}
I_{\alpha} \\
I_{\beta}
\end{array}\right]=\left[\begin{array}{cc}
1 & 0 \\
\frac{1}{\sqrt{3}} & \frac{2}{\sqrt{3}}
\end{array}\right]\left[\begin{array}{l}
I_{g a} \\
I_{g b}
\end{array}\right]
$$

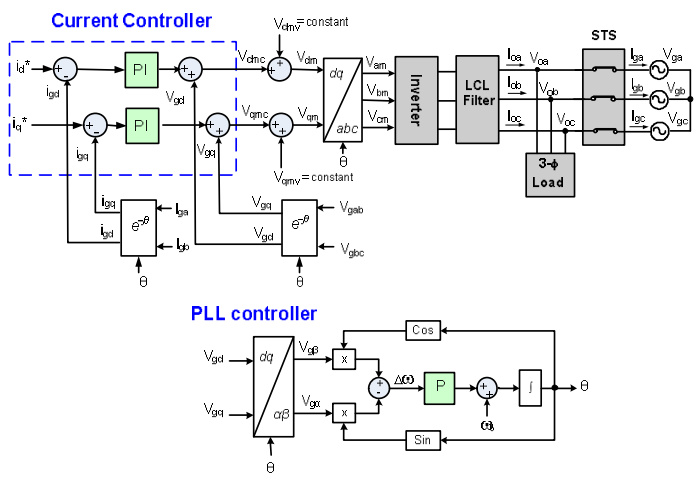

Figure 5. Block diagram for grid-tied mode.

$$
\left[\begin{array}{l}
I_{g d} \\
I_{g q}
\end{array}\right]=\left[\begin{array}{cc}
\cos \theta & -\sin \theta \\
\sin \theta & \cos \theta
\end{array}\right]\left[\begin{array}{l}
I_{\alpha} \\
I_{\beta}
\end{array}\right]
$$

The grid current $I_{g}$, which has been transformed into a synchronous frame by transformation (13), (14) and became dc quantities, is fed back and compared with the reference currents. The difference between $\mathrm{I}_{g}$ and $\mathrm{I}_{g}{ }^{*}$ generates a current error and then is passed to a current regulator using PI controller. The output of PI controller performs a regulating voltage and it is added to grid voltage $V_{g}$, which has been transformed into a synchronous frame by transformation (1), (15) and became dc quantities, and also is added to another dc quantities from voltage controller, which are $\mathrm{V}_{\mathrm{dmc}}$ and $\mathrm{V}_{\mathrm{qmc}}$, to generate the voltage references in dc quantities and then are transformed into a stationary by the inverse of Park's transformation. The final dcquantities are utilized as command voltages for generating PWM voltages. In this grid-tied mode, $\mathrm{V}_{\mathrm{dmc}}$ and $\mathrm{V}_{\mathrm{qmc}}$ will be not changed because the voltage regulator is not operating; therefore the 
output voltage at $\mathrm{PCC}$ are regulated by only $\mathrm{V}_{\mathrm{dm}}$ and $\mathrm{V}_{\mathrm{qm}}$.

\subsection{Current controller}

Figure 6 shows the Phasor diagram of command voltage $\mathrm{V}_{\mathrm{m}}$ for generating PWM voltage. The command voltage is obtained by two voltage components $\mathrm{V}_{\mathrm{mv}}$ and $\mathrm{V}_{\mathrm{mc}}$, where $\mathrm{V}_{\mathrm{mc}}$ is generated by current controller and $\mathrm{V}_{\mathrm{mv}}$ is generated by voltage controller.

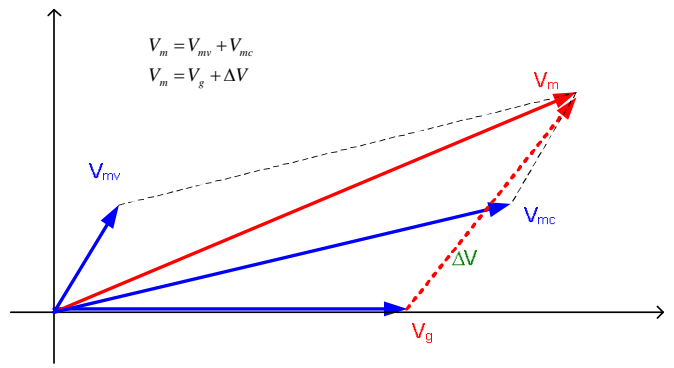

Figure 6. Phasor diagram of command voltage.

In the stand-alone mode, the current controller is not working so $\mathrm{V}_{\mathrm{mc}}$ does not change while $\mathrm{V}_{\mathrm{mv}}$ changes to regulate the output voltage of inverter through the command voltage $\mathrm{V}_{\mathrm{m}}$.

In the grid-tied mode, the voltage controller is not working so $\mathrm{V}_{\mathrm{mv}}$ does not change while $\mathrm{V}_{\mathrm{mc}}$ changes to regulate the injected current of inverter through the command voltage $\mathrm{V}_{\mathrm{m}}$.

\subsubsection{Off-grid mode to grid-tied mode}

When the power system is detected under normal operating condition, $\mathrm{CB}$ is close, the DG is controlled to operate in grid-tide mode. The below procedure is proposed to obtain the seamless transfer:

- Firstly, the PLL is switched from off-grid status $(\mathrm{S} 1=0)$ to grid-tied status $(\mathrm{S} 1=1)$ as shown in Figure 7. During this time, the voltage controller is still using the desired value as a voltage reference for regulating output voltage of inverter. End of this period, the phase of voltage at PCC will match about two grid voltage cycles.
- Secondly, when the phase of grid voltage and inverter voltage matches together, the reference voltage of voltage controller is switched from desired value $(\mathrm{S} 2=0)$ to grid value $(\mathrm{S} 2=1)$. The magnitude of inverter voltage and grid voltage will match about a grid voltage cycle.

- Finally, turn CB1 on and then increase gradually the reference of d-component current $I_{d}{ }^{*}$ and the reference of q-component current $I_{q}{ }^{*}$ to the desired values. The active power $P^{*}$ and reactive power $Q^{*}$ are obtained by following equations,

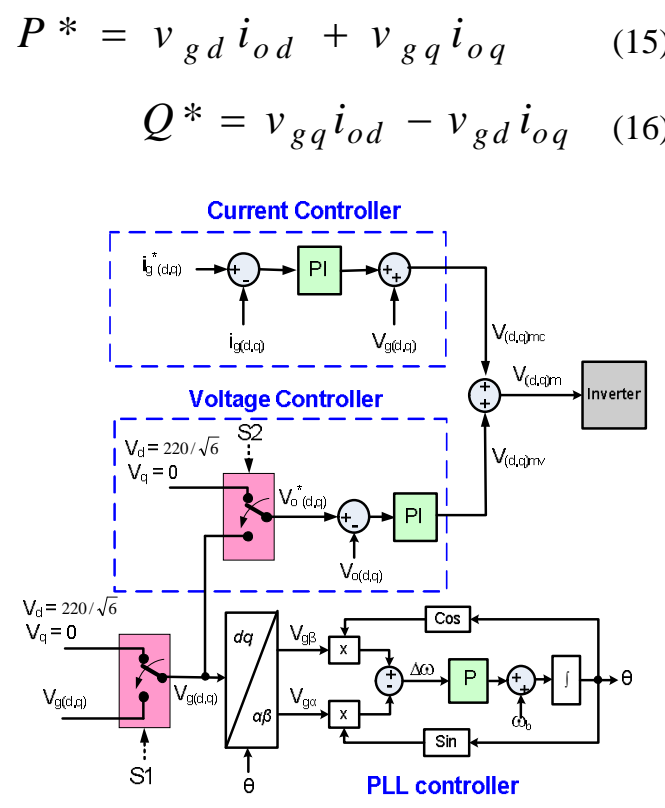

Figure 7. Synchronization for grid connection.

With this procedure, the transfer from offgrid mode to grid-tide mode will not cause any voltage or current spike on local load. So the seamless transfer was archived between off-grid mode and grid-tied mode.

\subsubsection{Grid-tied mode to off-grid mode:}

In grid-tied mode, the current controller is used to control the active power and reactive power into the grid. When a fault occurs on the grid side the protective device will be open, the current controller need to be disabled as soon as 
possible [14]. In this moment, the smooth transition can be obtained by this procedure:

- Firstly, the reference of active power and reactive power slowly reduce to zeros.

- Secondly, when active power and reactive power become zeros the AC switch is turned off. On the other hand, because the grid voltage is now not available so the PLL controller is switched to voltage mode.

With this proposed control method, the current controller transfer smoothly to voltage controller; therefore, the transfer from grid-tied mode to off-grid mode will not cause any voltage or current spike on local load during islanding operation. That is to say, the seamless transfer was archived between grid-tied mode and stand-alone mode.

\section{SIMULATION RESULTS}

The performance of the seamless transfer was carried out by computer simulation using PSIM and Visual $\mathrm{C}++$. Figure 7 shows the seamless transfer system for three-phase grid-interactive VSI with the parameters are given by the Table 1 below.

Table 1. Parameters for Simulation System

\begin{tabular}{|l|l|}
\hline The VSI rated power & $5 \mathrm{KW}$ \\
\hline The nominal voltage (line-line RMS) & $110 \mathrm{~V}$ \\
\hline The nominal frequency & $60 \mathrm{~Hz}$ \\
\hline The switching frequency & $8 \mathrm{KHz}$ \\
\hline The sampling time & $1 \mathrm{us}$ \\
\hline The DC link voltage of inverter & $250 \mathrm{~V}$ \\
\hline The filter inductor Li & $1.3 \mathrm{mH}$ \\
\hline The filter inductor Lg & $0.24 \mathrm{mH}$ \\
\hline The filter capacitor Cf & $10 \mathrm{uF}$ \\
\hline The resonant resister Rd & $1.5 \mathrm{Ohm}$ \\
\hline
\end{tabular}

Figure 8 shows the simulation results of the transition from stand-alone mode to grid-tied mode with seamless algorithm.
Figure 8 a shows the output voltage of inverter Voab at local load and the grid voltage Vgab of grid system. Figure $8 \mathrm{~b}$ shows the output current Ioa of inverter and the grid current Iga. The error of phase controller $\Delta \omega$ is shown in Figure $8 \mathrm{c}$ and the difference between grid voltage and output voltage of inverter is shown in Figure 8d. With proposed transition procedure, the simulation results presented the seamless transfer from standalone mode to grid-tied mode.

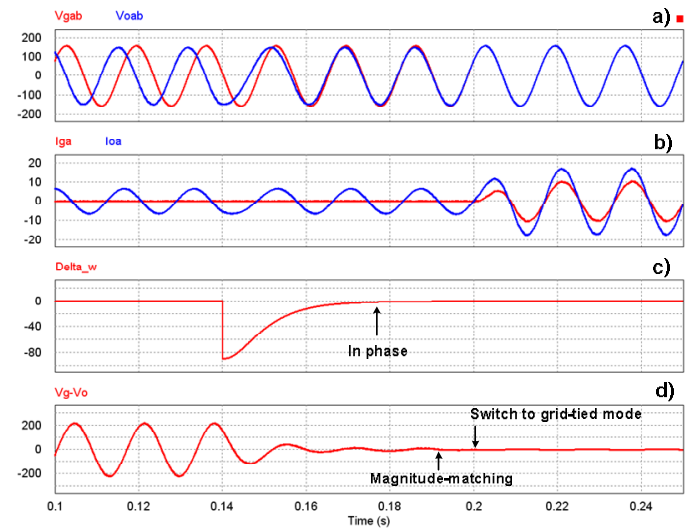

Figure 8. Transition from stand-alone mode to gridtied mode with seamless algorithm.

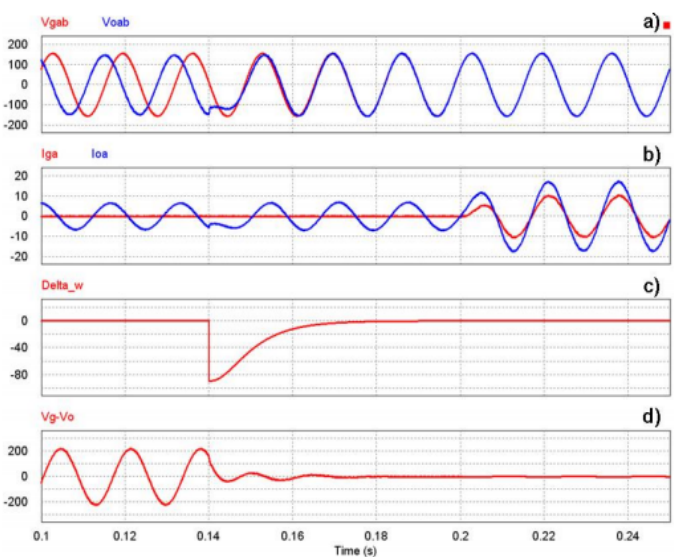

Figure 9. Transition from stand-alone mode to grid-tied mode without seamless algorithm.

Figure 9 shows the simulation results of the transition from stand-alone mode to grid-tied mode without seamless algorithm. The magnitude and phase of the output voltage of inverter can be

\section{Trang 16}


matched in this situation but it causes a distortion in the output voltage of inverter. The distortion of voltage depends on the phase difference between output voltage of inverter and voltage of grid system.

Figure 10 shows the simulation results of the transition from grid-tied mode to stand-alone mode. Figure 10a shows the output voltage of inverter Voab at local load and the grid voltage $\mathrm{Vgab}$ of grid system. Figure $10 \mathrm{~b}$ shows the output current Ioa of inverter and the grid current Iga. Figure 10c shows the grid voltage with RMS value.

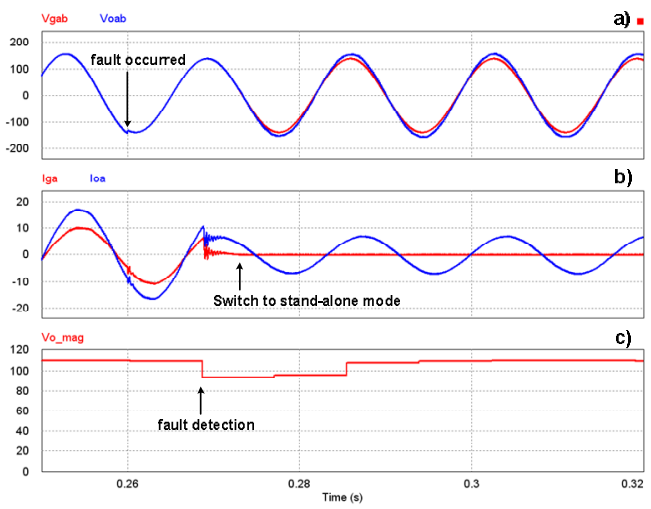

Figure 10. Simulation waveforms of the transition from grid-tied mode to stand-alone mode.

\section{EXPERIMENT RESULTS}

The performance of the seamless transfer has been built to carry out the theoretical algorithm. With this system, a DSP TMS320F28335 has been employed to control the inverter, display the signals for checking through DAC converter and interface with computer for remote control. The interface program used Visual $\mathrm{C}++$ software and the DSP program was coded by Code Composer Studio software. The experimental system was built as shown in Figure 7 with the parameters are given by the Table I above.

Figure 11 shows the experiment results of synchronization operation from stand-alone mode to grid-tied mode. The output voltage of inverter
Voab and the grid voltage Vgab are shown in this figure. The error of phase controller $\Delta \omega$ and the phase of system are displayed by using DAC converter.

Figure 12 shows the experiment results of the output voltage of inverter Voab, the inverter current Ioa and the grid current Iga in the operation from stand-alone mode to grid-tied mode.

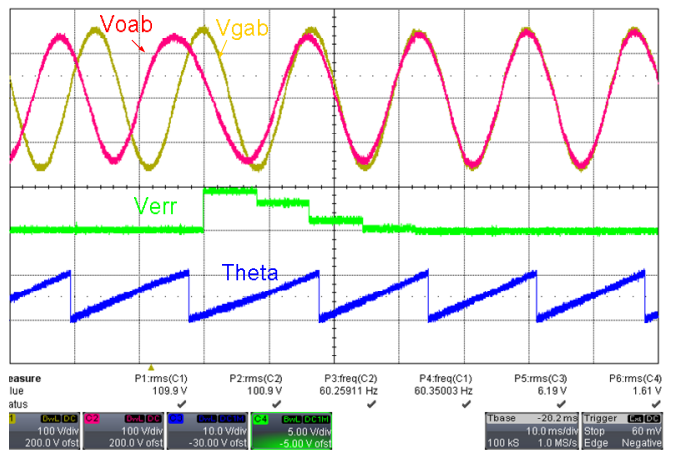

Figure 11. Experiment results of output voltage of inverter and grid voltage when transfer from to stand-alone mode to grid-tied mode.

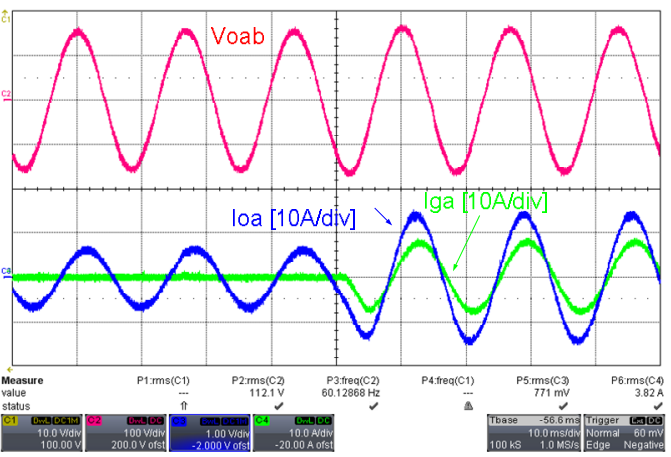

Figure 12. Experiment results of inverter current and grid current when transfer from to stand-alone mode to grid-tied mode.

Figure 13 shows the experiment results of the islanding operation from grid-tied mode to standalone mode. The output voltage of inverter Voab and the grid voltage Vgab are presented in this figure. The RMS value of grid voltage is displayed by using DAC converter. 


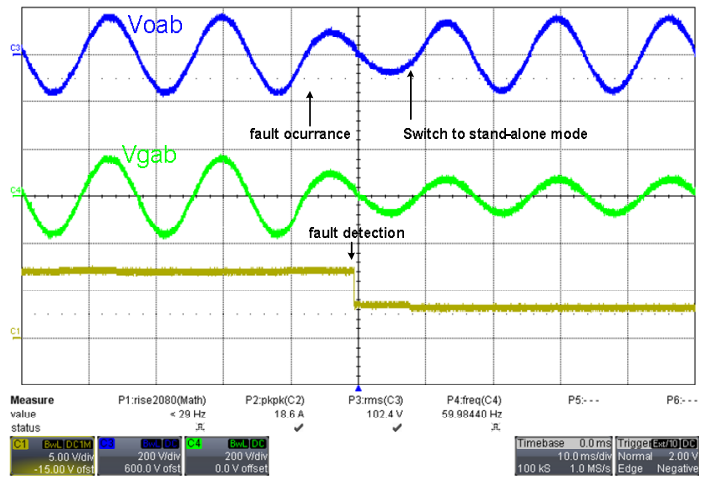

Figure 13. Experiment results of output voltage of inverter and grid voltage when transfer from grid-tied mode to stand-alone mode.

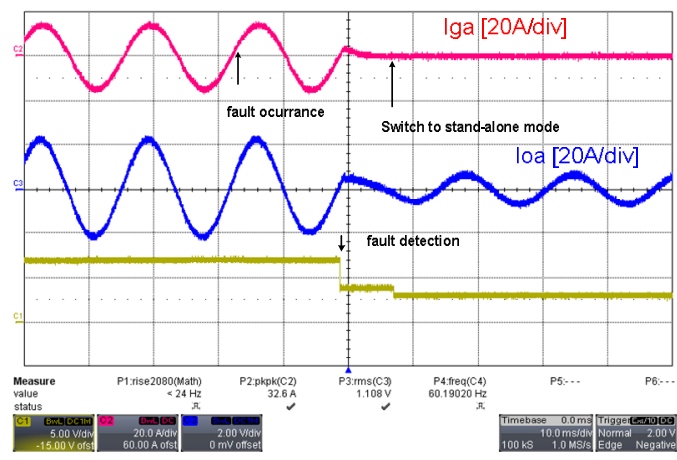

Figure 14. Experiment results of inverter current and grid current when transfer from grid-tied mode to stand-alone mode.
Figure 14 shows the experiment results of the islanding operation from grid-tied mode to standalone mode. The grid current Iga and the output current of inverter Ioa are presented in this figure. The RMS value of grid voltage is displayed by using DAC converter.

\section{CONCLUSION}

A seamless transfer for three-phase gridconnected inverter was suggested. The algorithm control guarantees a smooth profile voltage across the local load when the grid is being disconnected or reconnected. The simulation and experiment results have been presented to verify the proposed method.

\section{Trang 164}




\section{Chuyển mạch mềm với giải thuật bù tương tác cho nghịch lưu ba pha nối lưới}

\section{- Trần Thanh Vũ}

Đại học Quốc Tế Miền Đông, Việt Nam

- Nguyễn Đình Tuyên

- Phan Quốc Dũng

Trường Đại học Bách Khoa, ĐHQG-HCM, Việt Nam

\section{TÓM TÁT}

Bài báo này đề xuất một giải thuật điều khiển tương tác cho chuyển mạch mềm của bộ nghịch lưu ba giữa hai chế độ nối lưới và độc lập. Để đạt được sự chuyển đổi mềm giữa hai chế độ, bộ điều khiển áp và dòng được thiết kế để tạo ra xung PWM không có sự gián đoạn trong qua trình chuyển đổi giữa chế độ độc lập và chế độ nối lưới. Hơn nữa, một giải thuật PLL phù hợp được đề xuất để

Từ khóa: bộ nghịch lưu, PLL, bộ nghịch lưu nối lưới, chất lượng điện năng, điều khiển dòng, điều khiển áp.

\section{REFERENCES}

[1]. Hisao Watanabe, Toshihisa Shimizu, Gunji Kimura "A Novel Utility Interactive Photovoltaic Inverter with Generation Control Circuit" Industrial Electronics Society, 1998. IECON '98. Proceedings of the 24th Annual Conf. of the IEEE.

[2]. Naoto Kikuchi', Souichirou Shigeeda', Hiroshi Watanabe' Harashima', Tokuo Ohnishi", Fumio, "Single Phase Amplitude Modulation Inverter for Utility Interactive Photovoltaic System” 1999

[3]. T. and D. G. Holmes, "Grid current regulation of a three-phase voltage source inverter with an LCL input filter" 2003 lấy giá trị góc pha điện áp lưới liên tục mặc cho lưới điện bị ngắt. Với giải thuật đề xuất, bộ điều khiển vẫn đảm bảo chất lượng điện áp khi bộ nghịch lưu cung cấp cho tải cục bộ trong trường hợp lưới điện bị ngắt ra. Kết quả mô phỏng và thực nghiệm được trình bày trong bài báo để minh chứng tính đúng đắn của phương pháp đề xuất.
[4]. M. Prodanovic and T. C. Green, "Control and filter design of three-phase inverters for high power quality grid connection"

[5]. Q. Zeng and L. Chang, "Study of advanced current control strategies for three-phase gridconnected pwm inverters for distributed generation" 2005

[6]. R. Tirumala, N. Mohan, C. Henze, "Seamless transfer of grid-connected PWM inverters between utility-interactive and stand-alone modes," IEEE Appl. Power Electron. Conf. and Exposition, USA: Dallas, vol.2, pp.1081 - 1086, 2002.

[7]. Sangmin Jung, Youngsang Bae, Sewan Choi, Senior Member, IEEE, and Hyosung Kim, 
Member, IEEE, “A Low Cost Utility Interactive Inverter for Residential Fuel Cell Generation" 2007

[8]. G. Q. Shen, D. H. Xu, and X.M.Yuan, "A novel seamless transfer control strategy based on voltage amplitude regulation for utilityinterconnected fuel cell inverters with an LCL-filter" 2006

[9]. Tai-Sik Hwang, Kwang-Seob Kim, Byung-Ki Kwon, "Control Strategy of 600kW E-BOP for Molten Carbonate Fuel Cell Generation System" 2008

[10].Zhilei Yao, Lan Xiao, Yangguang Yan, "Seamless Transfer of Single-Phase GridInteractive Inverters Between GridConnected and Stand-Alone Modes," IEEE Trans. Power Electron., vol. 25, Issue 6, pp. 1597 - 1603, June 2010.

[11].Hyosung Kim, Taesik Yu, Sewan Choi, "Indirect Current Control Algorithm for Utility Interactive Inverters in Distributed Generation Systems", IEEE Trans. Power Electron., vol 23, issue 3, pp.1342-1347, May 2008.

[12].Junbum Kwon, Sunjae Yoon, and Sewan Choi, "Indirect Current Control for Seamless Transfer of Three-Phase Utility Interactive Inverters" 2012

[13].R. A. Walling, N. W. Miller, "Distributed generation islanding-implications on power system dynamic performance," IEEE Power Engineering Society Summer Meeting, USA: Chicago, vol.1, pp.92 - 96, July 2002.

[14].A. Rajabi-Ghahnavie, M. Parniani, M. FotuhiFiruzabad, "Investigating the effects of reactive power on islanding detection," Power System Technology Int. Conf., vol.2, pp.1067 - 1071, Nov. 2004.

[15].R. A. Walling, "Islanding issues for largescale wind generators interconnected to localdelivery distribution systems," IEEE Power \& Energy Society General Meeting, Canada: Calgary, pp. 1 - 4, July 2009.
[16].F. De Mango, M. Liserre, A. D. Aquila, "Overview of Anti-Islanding Algorithms for PV Systems. Part II: ActiveMethods," Power Electron. and Motion Control Conf., Italia: Portoroz, pp.1884 1889, Aug. 30 2006-Sept. 12006.

[17].Guoqiao Shen, Dehong Xu, Xiaoming Yuan, "A Novel Seamless Transfer Control Strategy Based on Voltage Amplitude Regulation for Utility-interconnected Fuel cell Inverters with an LCL-filter, " IEEE Power Electron. Specialists Conf., pp.1 - 6, June 2006.

[18].Qin Lei, Shuitao Yang, F. Z. Peng, "Multiloop control algorithms for seamless transition of grid-connected inverter," IEEE Appl. Power Electron. Conf. and Exposition, USA: Palm Springs, pp.844 - 848, Feb. 2010.

[19].Zeng Liu, Jinjun Liu, "Seamless transfer strategy with outer current loop for three phase inverter in distributed generation," IEEE Energy Conversion Congress and Exposition, USA: Atlanta, pp.3556 - 3560, Sept. 2010.

[20].I. J. Balaguer, Qin Lei, Shuitao Yang, U. Supatti, Fang Zheng Peng, "Control for GridConnected and Intentional Islanding Operations of Distributed Power Generation," IEEE Trans. Ind. Electron., vol. 58, Issue 1, pp. 147 - 157, Jan. 2011.

[21]. Wenqiang Zhao, Guozhu Chen, "Comparison of active and passive damping methods for application in high power active power filter with LCL-filter," Sustainable Power Generation and Supply Int. Conf., China: Nanjing, pp. 1 - 6, April 2009.

[22].Jae-Hyung Kim, Jun-Gu Kim, Young-Hyok Ji, Yong-Chae Jung, and Chung-Yuen Won, Senior Member, IEEE, "An Islanding Detection Method for a Grid-Connected System Based on the Goertzel Algorithm" IEEE Trans Power Electron., Vol. 26, pp. 1049-1055, April 2011.

[23].IEEE Standard for Interconnecting Distributed Resources with Electric. 